\title{
Analysis of Local Climate Variations Using Correlation between Satellite Measurements of Methane Emission and Temperature Trends within Physiographic Regions of Ukraine
}

\author{
Mikhail A. Popov, Sergey A. Stankevich, Yuri V. Kostyuchenko*, Anna A. Kozlova \\ Workgroup on Mathematical Modeling of Geo-Systems and Risk Analysis \\ Department of Heat \& Mass Exchange in Geo-Systems \\ Scientific Centre for Aerospace Research of the Earth, Kiev, Ukraine \\ Corressponding author: mpopov@casre.kiev.ua
}

(Received September 29, 2018; Accepted November 21, 2018)

\begin{abstract}
Paper aimed to the description of the methods of analysis and measurements of atmospheric greenhouse gases (GHG), especially, methane concentration using satellite tools for climate change model improvement. The experimental accuracy estimation of narrow-band spectral indices restoration by the wide-band multispectral image is performed. Three methods for narrow-band spectral indices restoration are analyzed. The method on the basis of spectra translation is recommended for practical application.
\end{abstract}

Keywords- Climate model, Atmosphere remote sensing, Satellite measurement, Methane emission model, Temperature trend, Physiographic region.

\section{Introduction}

Currently, climate change in Ukraine is quite obvious (Climate Change and Security, 2017). The dominant trend in climate change both global and regional is the temperature gradual increase (Smith and Pitts, 1997). In terms of human civilization, it should not unavoidable lead to total catastrophic consequences, but climate change is a deterrent for economic growth, living standards and social progress (Rezai et al., 2018) both on the global, and especially on the local scale (Kostyuchenko, 2012). Simulation and forecasting of climate change and analysis of its impact on local communities and ecosystems is a complex and insufficiently defined problem (Murphy et al., 2004).

Not only correct global ecological and circulation models but also local submodels, datasets and separate case analysis are required to solve this problem (Murphy, 2004; Belić, 2006; Lawrence et al., 2011). In many cases local models may be vary complicated and hard-linked to global models (Kostyuchenko et al., 2017; Kostyuchenko, 2018), so the statistical analysis of local data is also required. So, any detectable correlations of climate parameters with physically available measurements are very important.

In Ukraine, climate change occurs somewhat faster than in the world as a whole: at moment the average global temperature increment is estimated as $0.8^{\circ} \mathrm{C}$ per year, but in Ukraine, it is about $1{ }^{\circ} \mathrm{C}$ per year (Kogan et al. 2013). Climate warming is determined by many drivers, but greenhouse gas emissions play a very important role (Belić, 2006). Of course, the major contribution to the greenhouse effect is provided by carbon dioxide, and its influence in Ukraine has been investigated in detail (Lyalko, 2015). The territory of Ukraine includes a high fraction of 
International Journal of Mathematical, Engineering and Management Sciences

Vol. 4, No. 2, 276-288, 2019

https://dx.doi.org/10.33889/IJMEMS.2019.4.2-023

agrolandscapes, which have the ability to generate actively not only carbon dioxide, but also methane (Oertel et al., 2016).

Separate question is the methane emission from local wetlands under observed variations of heat and water regime (Lawrence et al., 2011; Meng et al., 2011). This problem should be analyzed both using the field measurement and satellite observations, which should be interpreted basing on the model of wetlands methane emission, adopted for local condition (Meng et al., 2011).

Therefore, basing on the generalized global models, we assume that methane emissions can have a certain statistical relation with the most important climatic parameter - temperature at long-term time series. The discovery a direct form of these relations, and to develop and verify the models of local wetlands methane emissions in view of general approach (Meng et al., 2011; Kostyuchenko, 2018) is the main purpose of this paper.

The paper is organized as follows. As the methodological basis of the further analysis, the models of global and local methane cycles are presented in the paper. The Community Climate System Model and Community Earth System Model were used as the global models. For the description of local methane emission have been developed a multilayer wetland methane production and consumption model, presented in the paper. A brief note on analysis of aleatiroc uncertainty, which is immanent to the developed model is presented. The methodological overview of satellite tools for detection of atmospheric concentrations of greenhouse gases (GHG) is presented in the paper. The next section describes the source data and methods used to detect correlation between methane emission and temperature, after it, the quantification is discussed, and finally the research conclusion is made.

\section{Methodological Notes: Methane Emission in the Context of GHG and Carbon Cycle Modeling}

\subsection{On the Methane Cycle Modeling: From Local to Global, Variables and Parameters}

If the problem of carbon oxides in the framework of global and local carbon cycle is considered with sufficient correctness, the problem of methane requiring more detailed analysis. The separate scientific task is to construct a local model describing the methane emission from wetlands, which could be linked with global emission, biospheric and climatic models, such as the corresponding carbon dioxide models.

The following way to construct this type of the model can be proposed in the framework general approach to GHG and carbon balance modeling (Kostyuchenko et al., 2017).

In the framework of the Community Climate System Model (Gent et al., 2011) and the Community Earth System Model (CESM1) was constructed CLM4Me model - a $\mathrm{CH}_{4}$ biogeochemistry model (Lawrence et al., 2011).

CLM4 includes modules to simulate plant photosynthesis, respiration, growth, allocation, and tissue mortality; energy, radiation, water, and momentum exchanges with the atmosphere; soil heat, moisture, carbon, and nitrogen dynamics; surface runoff and groundwater interactions; and snow and soil ice dynamics. Having a representation of these processes with some level of detail is important for estimating the controlling factors for $\mathrm{CH}_{4}$ production, consumption, and emission to the atmosphere. Results of modeling with CLM4Me were used in this study. 
International Journal of Mathematical, Engineering and Management Sciences

Vol. 4, No. 2, 276-288, 2019

https://dx.doi.org/10.33889/IJMEMS.2019.4.2-023

For $\mathrm{CH}_{4}$, the model accounts for production in the anaerobic fraction of soil $\left(\mathrm{P}, \mathrm{mol} \mathrm{m} \mathrm{s}^{-3} \mathrm{~s}^{-1}\right.$, ebullition $\left(\mathrm{E}, \mathrm{mol} \mathrm{m} \mathrm{s}^{-3}\right)$, aerenchyma transport $(A, \mathrm{~mol} \mathrm{~m})$, aqueous and gaseous diffusion $\left(F_{D}\right.$, mol m $\left.\mathrm{m}^{-2} \mathrm{~s}^{-1}\right)$, and oxidation $\left(O, \mathrm{~mol} \mathrm{~m}^{-3} \mathrm{~s}^{-1}\right)$ via a transient reaction diffusion equation

$\frac{\partial(R C)}{\partial t}=\frac{\partial F_{D}}{\partial z}+P(z, t)-E(z, t)-A(z, t)-O(z, t)$,

Here, $z(m)$ represents the vertical dimension, $t(s)$ is time, and $R$ accounts for gas in both the aqueous and gaseous phases: $R=\varepsilon_{a}+K_{H} \cdot \varepsilon_{\omega}$, with $\varepsilon_{\mathrm{a}}$ is the air-filled porosity, $\varepsilon_{\mathrm{w}}$ is the waterfilled porosity, and $\mathrm{K}_{\mathrm{H}}$ is the partitioning coefficient for the species of interest.

Because most of the climate models, in particular CLM4, does not currently have a local wetland representation that includes details relevant to $\mathrm{CH}_{4}$ production (wetland specific plants, anoxia controls on soil organic matter turnover), nor is the inundated fraction used by the $\mathrm{CH}_{4}$ submodel integrated with the CLM4 soil hydrology and temperature predictions, this task should be solved using local models and data.

In CLM4Me, $\mathrm{CH}_{4}$ production in the anaerobic portion of the soil column is related to the gridcell estimate of heterotrophic respiration from soil and litter $\left(R_{H} ; \mathrm{mol} \mathrm{Cm}^{-2} \mathrm{~s}^{-1}\right)$ corrected for its soil temperature $\left(T_{s}\right)$ dependence, soil temperature through a $Q$ factor $\left(f_{T}\right), p H\left(f_{p H}\right.$; (Meng et al., $2011)$ ), redox potential $\left(f_{p E}\right)$, and a factor accounting for the seasonal inundation fraction $(S)$

$P=R_{H} f_{C_{4}} f_{T} f_{p H} f_{p E} S$,

here, $f_{\mathrm{CH} 4}$ is the baseline fraction of anaerobically mineralized $\mathrm{C}$ atoms becoming $\mathrm{CH}_{4}$.

Assuming that $\mathrm{CH}_{4}$ production is directly related to heterotrophic respiration implies the assumption that there are no time delays between fermentation and $\mathrm{CH}_{4}$ production, and that soil organic matter can be treated uniformly with respect to its decomposition under either aerobic or anaerobic conditions.

The effect of seasonal inundation is also included in CLM4Me model. It was determined, that in the continuously inundated wetland, anoxia suppresses decomposition, leading to a larger soil organic matter stock, partially compensating the effect of anoxia on decomposition rates. The compensation is complete (respiration rates are unchanged) if i) soil decomposition is a linear function of pool size; ii) the fully anaerobic decomposition rate is a fixed factor of the aerobic rate; and iii) the soil is in equilibrium. At the same time, a tropical seasonally inundated system may experience extensive decomposition during the dry season but emit most of its $\mathrm{CH}_{4}$ during the wet season. Calculation is shows, that because the equilibrium carbon stock will be smaller, the $\mathrm{CH}_{4}$ fluxes will be smaller than the annual wetland even during the wet season.

In CLM4Me, was used a simplified scaling factor to calculate the impact of seasonal inundation on $\mathrm{CH}_{4}$ production

$$
S=(\beta(f-\bar{f})+\bar{f}) / f, S \leq 1
$$


where $f$ is the instantaneous inundated fraction, $\bar{f}$ is the annual average inundated fraction (evaluated for the previous calendar year) weighted by heterotrophic respiration, and $\beta$ is the anoxia factor that relates the fully anoxic decomposition rate to the fully oxygen-unlimited decomposition rate.

Also it may be assessed a global $\mathrm{CH}_{4}$ flux and atmospheric methane uptake using inundation phenomena as (Arah and Stephen, 1998)

$\varphi=\frac{1}{1-\eta \cdot C_{O 2}}$

here, $\varphi$ is the factor by which $\mathrm{CH}_{4}$ production is inhibited above the water level (compared to production as calculated in Eq. 2), $\mathrm{C}_{\mathrm{O} 2}\left(\mathrm{molm}^{-3}\right)$ is the bulk soil oxygen concentration, and $\eta=400 \mathrm{~m}^{3} \mathrm{~mol}^{-1}$.

Using the CLM4Me model it is possible to calculate global distributions of methane emissions in view of climate change. At the same time the model of wetland is still required.

As the local addition linked to global models, a structural mathematical model of local $\mathrm{CH}_{4}$ production and oxygenation in wetlands may be proposed.

Model is based on description of acetoclastic methane production (Lieth, 1975), where stratification of environment and velocity of substrates input are described as (Cao et al., 1996). Model equations can be presented in the combined form

$$
\begin{aligned}
& \frac{d x_{g a}}{d t}=x_{g a}\left(\mu_{g a}-\mu_{d g a}\right), \\
& \frac{d x_{g h}}{d t}=x_{g h}\left(\mu_{g h}-\mu_{d g h}\right), \\
& \frac{d x_{t}}{d t}=x_{t}\left(\mu_{t}-\mu_{d t}\right) .
\end{aligned}
$$

where the velocity of growth of methano-trophic and methano-genetic biomass

$$
\begin{aligned}
& \mu_{g a}=\frac{\mu_{\max g a} \cdot s_{H}}{s_{H}+K_{s g a}+\left(s_{H}^{2} / K_{i}\right)}, \\
& \mu_{g h}=\frac{\mu_{\max g h} \cdot\left[H^{+}\right]}{\left[H_{2}\right]+K_{s g h}} \\
& \mu_{t}=\frac{\mu_{\max t} \cdot C_{h l}}{K_{s l}+C_{h l}}
\end{aligned}
$$


International Journal of Mathematical, Engineering and Management Sciences

Vol. 4, No. 2, 276-288, 2019

https://dx.doi.org/10.33889/IJMEMS.2019.4.2-023

$s_{H a}=s_{a} \frac{\left[H^{+}\right]}{K_{a}+\left[H^{+}\right]}$,

$\frac{d s_{a}}{d t}=D_{2}\left(s_{i n}-s_{a}\right)-\frac{\mu_{g a} \cdot x_{g a}}{Y_{x g a}}+a c c$,

$\frac{d\left[H_{2}\right]}{d t}=D_{2}\left(\left[H_{2}\right]_{i n}-\left[H_{2}\right]\right)-\frac{\mu_{g h} \cdot x_{g h}}{Y_{x g h}}+h y d$.

So, the velocity of methane production and consumption

$$
\begin{aligned}
& Q_{c h 4 g a}=k Y_{C H 4 x g a} \mu_{g a} x_{g a}, \\
& Q_{c h 4 g h}=k Y_{C H 4 x g h} \mu_{g h} x_{g h}, \\
& Q_{c h 4 t}=\mu \frac{x_{t}}{Y_{x t s}} .
\end{aligned}
$$

And methane concentration dynamics in upper and lower layers of wetland

$$
\begin{aligned}
& \frac{d C_{h 1}}{d t}=k g_{1}\left(C_{h 2}-C_{h 1}\right)-k g_{2}\left(C_{h 1}-C_{a}\right)-Q_{C H 4 t}, \\
& \frac{d C_{h 2}}{d t}=Q_{C H 4 g a}+Q_{C H 4 g h}-k g_{1}\left(C_{h 2}-C_{h 1}\right) .
\end{aligned}
$$

In these equations

$x_{t}, x_{g a}, x_{g h}, \mu_{t}, \mu_{g a}, \mu_{g h}, s_{a}, s_{H a},\left[H_{2}\right], C_{h 1}, C_{h 2}, Q_{C H 4 g a}, Q_{C H 4 g h}, Q_{C H 4 t}$.

Solution of these equations (5)-(18) allows to fulfill a carbon flux matrix (Kostyuchenko et al., 2017) with more correct data on the local scale. The whole approach (1)-(18) might be used to calculate integrated methane emissions from natural systems in multi-scale range, which is useful for using different measurement tools - in-field gasometry, satellite data, statistics, etc. Using this multi-scale methane wetlands emission model in the tasks of carbon emission analysis is the way to reduce uncertainties, both aleatorical and epistemic in the climate models.

\subsection{Notes on Uncertainty Analysis in Carbon Balance Models}

For error and uncertainty analysis in integrated models (Kostyuchenko, 2018) of carbon balance traditionally using data of statistically independent sources. For it may be used data of satellite observations (Movchan et al., 2014).

In (Shvidenko et al., 2010) algorithm for determination of standard error $m_{y}^{2}$ of carbon flux $Y=f\left(X_{i}\right)$, which defined as function of random distribution $X_{\mathrm{i}}$ with $i=1,2, \ldots k$ is proposed in form 
International Journal of Mathematical, Engineering and Management Sciences

Vol. 4, No. 2, 276-288, 2019

https://dx.doi.org/10.33889/IJMEMS.2019.4.2-023

$m_{y}^{2}=\sum_{i=1}^{k}\left(\frac{d Y}{d X_{i}} m_{i}\right)^{2}+2 \sum_{i>j}\left(\frac{d Y}{d X_{i}}\right)\left(\frac{d Y}{d X_{j}}\right) r_{i j} m_{X_{i}} m_{X_{j}}$

where $r_{i j}$ - coefficients of correlation between distributions $X_{i}$ and $X_{j}$.

Using this algorithm it is possible to estimate an error of carbon fluxes in all components of the system studied basing on all available data. Satellite observation data is also possible to integrate into this algorithm.

Relative integrated reliability of data can be estimated separately. It can be done through comparison of geospatial data of land cover distribution (obtained from satellite image classification), ecological modeling, geostatistics and inventory, as well as analysis of atmospheric concentration of GHG controlled from satellites. For this purpose could be used "agreement index of suitability" (Shvidenko et al., 2010) as the measure of corresponding of normalized distributions

$S_{n m}=\frac{1}{q} \sqrt{\sum_{j=1}^{q}\left(x_{n j}^{n o r m}-x_{m j}^{n o r m}\right)^{2}}$, where $x_{j}^{n o r m}=\frac{x_{j}-x_{j \min }}{x_{j \max }-x_{j \min }}$

where $q$ - descriptive parameters; $n$ - sites of studied area; $m$ - sets of statistics (for example, departmental data); $x$ - measured values of parameter $j$. Sites of studied area should correspond to land cover classification, according to (Kopachevsky et al. 2016; Kostyuchenko et al., 2017 October).

Mutual consistency of data distribution can be assessed using this method, and so we can more correctly combine disparate data, and minimize errors (aleatoric uncertainty).

Therefore, using of integrated models of carbon balance, especially regionalized with satellite data, allows calculate ecological and climate-related change more accurately. So modeling is suitable part of security management.

\subsection{Satellite Tools for GHG Monitoring}

As an example of algorithm for atmosphere composition and conversion radiation parameters to separate gases concentration, we can use approach (Buchwitz et al., 2005; Schneising et al., 2009) developed and used for wide range of satellite sensor. This algorithm (Weighting Function Modified Differential Optical Absorption Spectroscopy-WFM-DOAS) allows obtain concentrations of $\mathrm{CO}_{2}, \mathrm{CH}_{4}$ and $\mathrm{O}_{2}$ using satellite observations data (Schneising et al., 2009).

This algorithm is based on least squares method for downscaling of selected vertical atmospheric profiles. Parameters are defining by direct observations of vertical characteristics of the atmosphere. Logarithm of linearized radiation transfer, which is defined by the atmosphere model and observation data, together with polynomial $P_{i}(\mathbf{a})$ is reducing to logarithm of relation of satellite measured radiation and solar radiation (i.e. to the normalized solar radiation $I^{o b s}$ ). Integrated equation of WFM-DOAS algorithm can be presented as (Buchwitz et al., 2005)

$\sum_{i=1}^{m}\left(\ln I_{i}^{\mathrm{obs}}-\ln I_{i}^{\mathrm{mod}}(\hat{\mathbf{V}}, \hat{\mathbf{a}})\right)^{2} \equiv\|\mathbf{R E S}\|^{2} \rightarrow \min$ 
International Journal of Mathematical, Engineering and Management Sciences

Vol. 4, No. 2, 276-288, 2019

https://dx.doi.org/10.33889/IJMEMS.2019.4.2-023

In this equation the model of linear radiation transport is presented as

$\ln I_{i}^{\bmod }(\hat{\mathbf{V}}, \hat{\mathbf{a}})=\ln I_{i}^{\bmod }(\overline{\mathbf{V}})+\left.\sum_{j=1}^{J} \frac{\partial \ln I_{i}^{\bmod }}{\partial V_{j}}\right|_{\bar{V}_{j}} \times\left(\hat{V}_{j}-\bar{V}_{j}\right)+P_{i}(\hat{\mathbf{a}})$

Index $i$ refers a wavelength of image pixel $i$. components of vector $\mathrm{V}$, denoted as $\mathrm{V}_{\mathrm{j}}$, determine vertical columns of all gases, which has absorption lines in selected spectral range. Factors of vertical distribution $\mathrm{V}_{\mathrm{j}}$ and polynomial coefficients of vector a using as reduction parameters. Also the atmosphere temperature profile is used as parameter of smoothing.

Calculation parameters are determined as a minimum (on least squares method) between measured radiation $\left(\ln I^{o b s}{ }_{i}\right.$ ) and modeled radiation $\left(\ln I^{m o d}{ }_{i}\right.$ ), so by the length of vector RES (in particular, its components $\mathbf{R E S}_{\mathrm{i}}$ for every spectral measurement $i$ ).

For determination of content of carbon dioxide using average on observation depth dry air molar fraction of this gas, measured at the same time with oxygen. So, average on observation depth carbon dioxide concentration $\mathrm{XCO}_{2}$ can be calculated as

$\mathrm{XCO}_{2}=\frac{\mathrm{CO}_{2}^{\mathrm{col}}}{\left(\mathrm{O}_{2}^{\mathrm{col}} / \mathrm{O}_{2}^{\mathrm{mf}}\right)}$

where $\mathrm{CO}_{2}{ }_{2}$ is received absolute content of $\mathrm{CO}_{2}$ (molecules on $\mathrm{cm}^{2}$ ), $\mathrm{O}^{\mathrm{col}}{ }_{2}$ the same for $\mathrm{O}_{2}, \mathrm{O}^{\mathrm{mf}}{ }_{2}$ - expected (averaged on observation depth) oxygen molar fraction reduced to dry air $(0,2095)$.

This is the way to calculate tropospheric concentration of gas from radiation intensity in frame of its absorption band. Method in details is described in (Buchwitz et al., 2005).

The similar way we can use for determination of other gases concentration, for example, methane. But concentration of carbon dioxide instead oxygen can be utilized in this algorithm (Schneising et al., 2009).

$\mathrm{XCH}_{4}=\frac{\mathrm{CH}_{4}^{c o l}}{\mathrm{CO}_{2}^{c o l} / \mathrm{CO}_{2}^{m f}}$

where, $\mathrm{CH}_{4}^{\mathrm{col}}$ is received absolute content of $\mathrm{CH}_{4}$ (molecules on $\mathrm{cm}^{2}$ ), $\mathrm{CO}^{\mathrm{col}}{ }_{2}$ the same for $\mathrm{CO}_{2}$, $\mathrm{CO}^{\mathrm{mf}}{ }_{2}$ - expected (averaged on observation depth) carbon dioxide molar fraction reduced to dry air. For $\mathrm{CO}_{2}^{\mathrm{mf}}{ }_{2}$ using constant $370 \mathrm{ppm}$.

\section{Materials and Methods}

First, the near-ground temperature data were obtained from NOAA National Center for Environmental Information (https://www.ncdc.noaa.gov/data-access/land-based-stationdata/land-based-datasets). The Global Summary of the Day (GSOD) dataset was used which included daily/monthly records of more than 9,000 ground climatic stations around the world. The most representative physiographic regions of Ukraine were chosen for analysis, namely the forest zone of Polesie and the steppe zone at the south of Ukraine (VI National Communication, 2014). The location of these regions is shown in Figure 1 map. 
International Journal of Mathematical, Engineering and Management Sciences

Vol. 4, No. 2, 276-288, 2019

https://dx.doi.org/10.33889/IJMEMS.2019.4.2-023

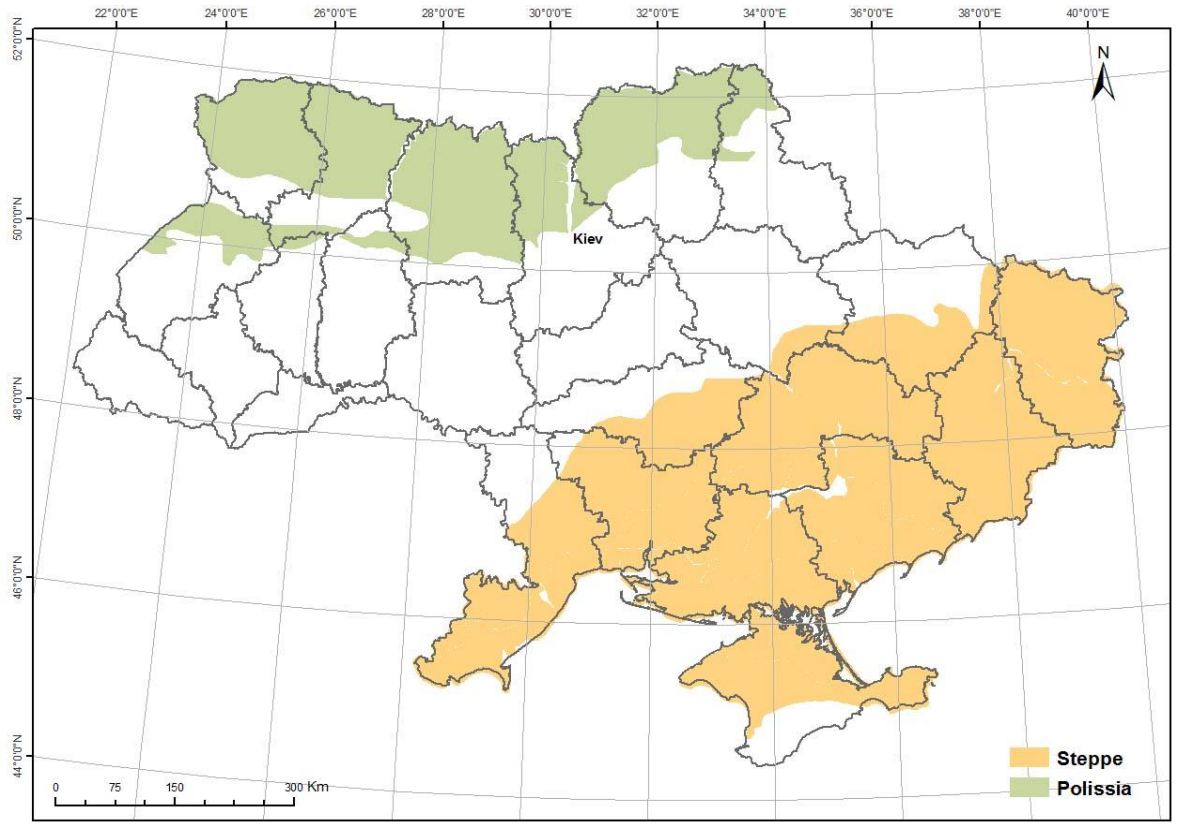

Figure 1. The Polesie $(a)$ and the Steppe $(b)$ physiographic regions of Ukraine

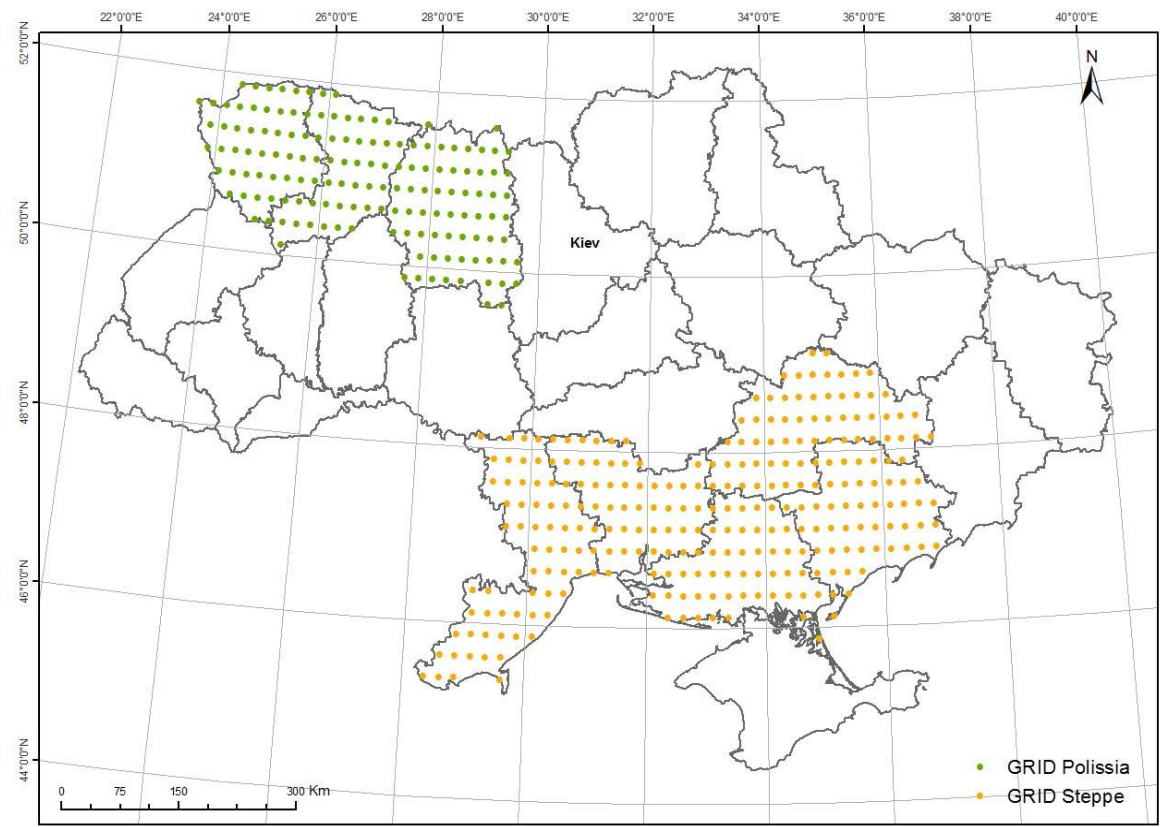

Figure 2. The grid of satellite measurements of methane atmospheric concentration over physiographic regions of Ukraine 
The GSOD dataset contained records from 6-7 ground climatic stations inside each region for the 2002-2016 period. Monthly temperature data averaged within each region.

The AIRX3STD data product provided by the NASA Goddard Earth Sciences (GES) Data and Information Services Center (https://disc.gsfc.nasa.gov/) was used to estimate the methane atmospheric concentration. This Level $31 \times 1^{\circ}$ gridded daily product is acquired by AIRS (optical spectrometer) and AMSU (microwave sounder) sensors installed onboard the second (Aqua) satellite of Earth Observing System (EOS) polar-orbiting platform also during 2002-2016. Spatial sub-setting and monthly averaging of satellite measurements of methane atmospheric concentration in the Polesie and Steppe regions was carried out using the Giovanni specialized web-service (https://giovanni.gsfc.nasa.gov/) of Goddard Space Flight Center (GSFC). Coverage of chosen physiographic regions of Ukraine with a grid of satellite measurements of methane atmospheric concentration is shown in the Figure 2 map.

In this way two synchronous time series - both temperature and methane atmospheric concentration - with 1 month temporal resolution were obtained for each of two studied physiographic regions of Ukraine during 2002-2016.

\section{Results and Discussion}

The primary method for the obtained time series analysis is trend extraction. The specified time series and ones trends are shown in Figure 3 diagrams.

All analyzed time series are characterized by an evident seasonal periodicity. This may explain the high correlation between the temperature and methane atmospheric concentration, which is 0.9995 in both physiographic regions. Since the time interval of available satellite observations is rather short by climatic standards, the extracted trends can be considered as linear. In the Polesie region, a slightly higher ( $0.016 \mathrm{~K}$ per month), as opposed to the Steppe region $(0.0155 \mathrm{~K}$ per month) monthly temperature increment is observed, although the methane rate is lower: $5.72 \cdot 10^{15}$ molecules $/ \mathrm{m}^{3}$ per month for Polesie and $5.89 \cdot 10^{15}$ molecules $/ \mathrm{m}^{3}$ per month for the Steppe. Accordingly, the cross-coupling ratio of the temperature increment with the methane emission rate for the Polesie region is approximately $5 \%$ higher than for the Steppe region - 2.802 against $2.645 \mathrm{mK}$ per petamolecules/m3 per month. Perhaps this phenomenon is associated with a lower fraction of open soils and plowed lands inside the Ukrainian Polesia, as well as with other type of long-term dynamics of vegetation cover (Ghazaryan et al., 2016). 
International Journal of Mathematical, Engineering and Management Sciences

Vol. 4, No. 2, 276-288, 2019

https://dx.doi.org/10.33889/IJMEMS.2019.4.2-023



$a$
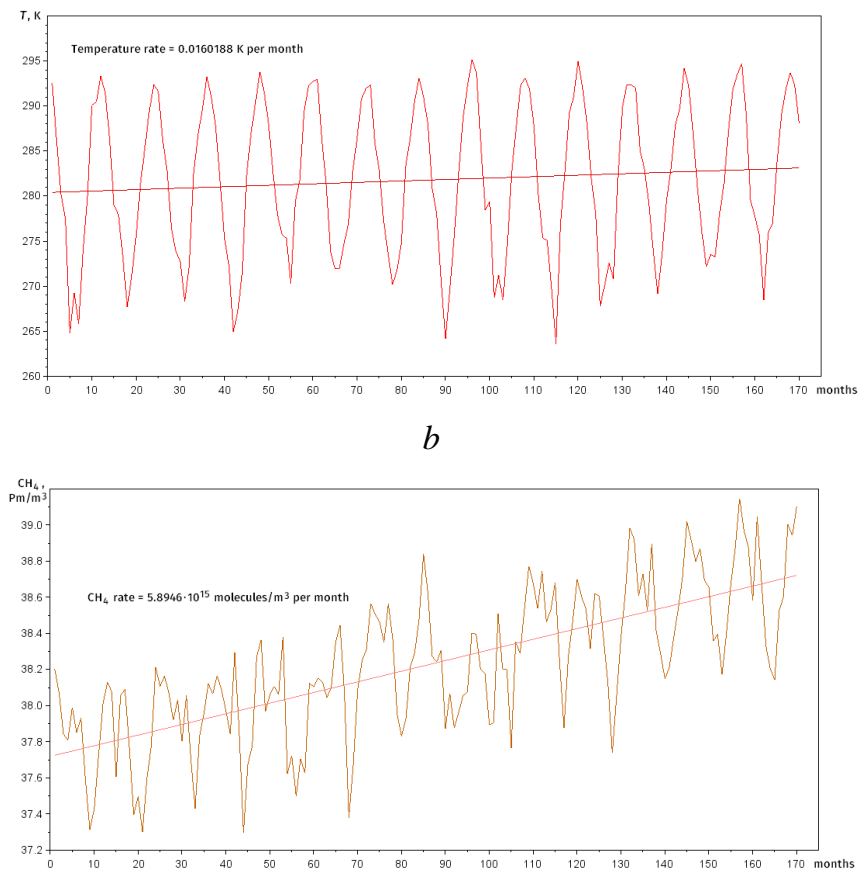

$c$

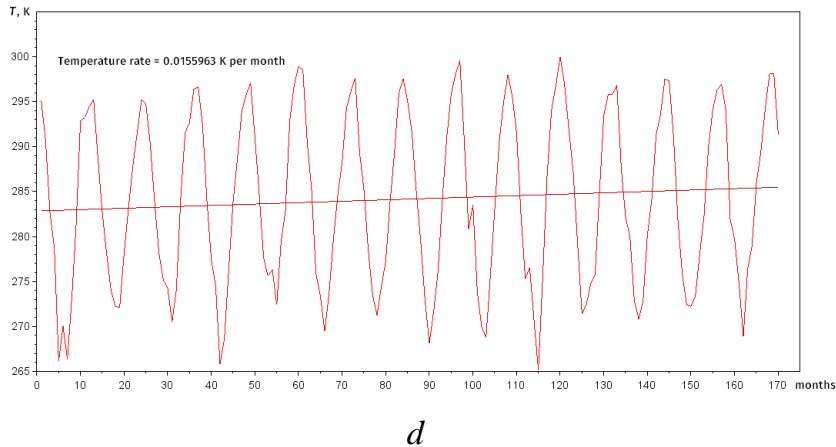

Figure 3. Obtained time series of methane atmospheric concentration $(a, c)$ and near-ground temperature $(b$, $d$ ) over Polesie $(a, b)$ and Steppe $(c, d)$ physiographic regions of Ukraine 
International Journal of Mathematical, Engineering and Management Sciences

Vol. 4, No. 2, 276-288, 2019

https://dx.doi.org/10.33889/IJMEMS.2019.4.2-023

To the further detail analysis of obtained relations should be used varied sophisticated methods spatially and temporally distributed data, of mapping (Rushdi and Ba-Rukab, 2017) and statistics with controlled parameters of reliability (Amrutkar and Kamalja, 2017).

\section{Conclusion}

Thus, the stable statistical relationship between methane emission and temperature increase is identified for two typical physiographic regions of Ukraine - both for Polesie and for Steppe. Because the satellite measurements of methane emissions are available daily from several different atmosphere remote sensing systems (Jacob et al., 2016), in our opinion ones can be used as either of the predictors for ongoing climate change.

Development of theoretical background and practicing of regional climate parameters simulation and forecasting, including temperature, should be the key focus of future research, first of all on the analysis of potential threats and damage, connected with climate change using statistical approaches (Lyalko, 2015; Mizutani and Nakagawa, 2018; Shah et al., 2018). General background for it is also proposed.

\section{Conflict of Interest}

The authors confirm that there is no conflict of interest to declare for this publication.

\section{Acknowledgement}

The authors would like to express their sincere thanks to the referee and for their valuable suggestions towards to the improvement of the paper. The authors are also grateful to colleagues from the International Institute for Applied Systems Analysis (IIASA) as well as from the American Meteorological Society (AMS) and American Statistical Association (ASA) for their critical and constructive comments and suggestions, and for presented important data and models.

This research was supported by the Science and Technology Center in Ukraine (STCU) - STCU Project \#6165 (2017) and by the National Academy of Sciences (NAS) of Ukraine - Resolution of the Presidium of NAS of Ukraine No 254 (2016).

\section{References}

Amrutkar, K. P., \& Kamalja, K. K. (2017). An overview of various importance measures of reliability system. International Journal of Mathematical, Engineering and Management Sciences, 2(3), 150-171.

Arah, J. R. M., \& Stephen, K. D. (1998). A model of the processes leading to methane emission from peatland. Atmospheric Environment, 32(19), 3257-3264.

Belić, D. S. (2006). Global warming and greenhouse gases. Facta Universitatis Series: Physics, Chemistry and Technology, 4(1). 45-55.

Buchwitz, M. D., Beek, R. D., Burrows, J. P., Bovensmann, H., Warneke, T., Notholt, J., \& Heimann, M. (2005). Atmospheric methane and carbon dioxide from SCIAMACHY satellite data: initial comparison with chemistry and transport models. Atmospheric Chemistry and Physics, 5(4), 941-962.

Cao, M., Marshall, S., \& Gregson, K. (1996). Global carbon exchange and methane emissions from natural wetlands: Application of a process based model. Journal of Geophysical Research: Atmospheres, 101(D9), 14399-14414. 
International Journal of Mathematical, Engineering and Management Sciences

Vol. 4, No. 2, 276-288, 2019

https://dx.doi.org/10.33889/IJMEMS.2019.4.2-023

Gent, P. R., Danabasoglu, G., Donner, L. J., Holland, M. M., Hunke, E. C., Jayne, S. R., Lawrence, D. M., Neale, R. B., Rasch, P. J., Vertenstein, M., Worley, P. H., Zong-Liang Yang, Z.-L., \& Zhang, M. (2011). The community climate system model version 4. Journal of Climate, 24(19), 4973-4991.

Ghazaryan, G. Dubovyk, O., Kussul, N., \& Menz G. (2016). Towards an improved environmental understanding of land surface dynamics in Ukraine based on multi-source remote sensing time-series datasets from 1982 to 2013. Remote Sensing, 8(8). A.617. 16 p. http://www.mdpi.com/2072$4292 / 8 / 8 / 617$.

Jacob, D. J., Turner, A. J., Maasakkers, J. D., Sheng, J., Sun, K., Liu, X., \& Frankenberg, C. (2016). Satellite observations of atmospheric methane and their value for quantifying methane emissions. Atmospheric Chemistry and Physics, 16(22), 14371-14396.

Kogan, F. Adamenko, T., \& Guo, W. (2013). Global and regional drought dynamics in the climate warming era. Remote Sensing Letters, 4(4), 364-372.

Kopachevsky, I., Kostyuchenko, Y. V., \& Stoyka, O. (2016). Land use drivers of population dynamics in tasks of security management and risk assessment. International Journal of Mathematical, Engineering and Management Sciences, 1(1), 18-25.

Kostyuchenko, Y. V. (2018). On the methodology of satellite data utilization in multi-modeling approach for socio-ecological risks assessment tasks: a problem formulation. International Journal of Mathematical, Engineering and Management Sciences, 3(1), 1-8.

Kostyuchenko, Y. V., Kopachevsky, I., Zlateva, P., Stoyka, Y., \& Akymenko, P. (2012). Role of systemic risk in regional ecological long-term threats analysis. Sustainable Civil Infrastructures-Hazards, Risk, Uncertainty, 551-556. Proc. of the $5^{\text {th }}$ Asian-Pacific Symposium on Structural Reliability and its Applications. ISBN: 978-981-07-2219-7.

Kostyuchenko, Y. V., Movchan, D., Artemenko, I., \& Kopachevsky, I. (2017). Stochastic approach to uncertainty control in multiphysics systems: modeling of carbon balance and analysis of GHG emissions using satellite tools. In Mathematical Concepts and Applications in Mechanical Engineering and Mechatronics (pp. 350-378). IGI Global, USA.

Kostyuchenko, Y. V., Yuschenko, M., Movchan, D., \& Kopachevsky, I. (2017, October). Analysis of economic values of land use and land cover changes in crisis territories by satellite data: models of socio-economy and population dynamics in war. In Earth Resources and Environmental Remote Sensing/GIS Applications VIII (Vol. 10428, p. 104280C). International Society for Optics and Photonics.

Lawrence, D. M., Oleson, K. W., Flanner, M. G., Thornton, P. E., Swenson, S. C., Lawrence, P. J., Zeng, X., Yang, Z.-L., Levis, S., Sakaguchi, K., Bonan, G. B., \& Slate, A. G. (2011). Parameterization improvements and functional and structural advances in version 4 of the Community Land Model. Journal of Advances in Modeling Earth Systems, 3. M03001. 10.1029/2011MS000045.

Lieth, H. (1975). Primary production of the major vegetation units of the world. In Primary Productivity of the Biosphere (pp. 203-215). Springer, Berlin, Heidelberg.

Lyalko, V. I. (2015) Greenhouse effect and climate changes in Ukraine: assessments and consequences. Kiev, Naukova Dumka, 284p.

Meng, L., Hess, P. G. M., Mahowald, N. M., Yavitt, J. B., Riley, W. J., Subin, Z. M., Lawrence, D. M., Swenson, S. C., Jauhiainen, J., \& Fuka, D. R. (2011). Sensitivity of wetland methane emissions to model assumptions: application and model testing against site observations, Biogeosciences Discuss., 8 , 6095-6160, doi:10.5194/bgd-8-6095-2011, 2011.

Mizutani, S., \& Nakagawa, T. (2018). Maintenance overtime policy with cumulative damage. International Journal of Mathematical, Engineering and Management Sciences, 3(2), 123-135. 
International Journal of Mathematical, Engineering and Management Sciences

Vol. 4, No. 2, 276-288, 2019

https://dx.doi.org/10.33889/IJMEMS.2019.4.2-023

Movchan, D., Kostyuchenko, Y. V., Marton, L., Frayer, O., \& Kyryzyuk, S. (2014). Uncertainty analysis in crop productivity and remote estimation for agricultural risk assessment. In Vulnerability, Uncertainty, and Risk: Quantification, Mitigation, and Management (pp. 1008-1015).

Murphy, J. M., Sexton, D. M., Barnett, D. N., Jones, G. S., Webb, M. J., Collins, M., \& Stainforth, D. A. (2004). Quantification of modelling uncertainties in a large ensemble of climate change simulations. Nature, 430(7001), 768-772.

Oertel, C., Matschullat, J., Zurba, K., Zimmermann, F., \& Erasmi, S. (2016). Greenhouse gas emissions from soils-a review. Chemie der Erde-Geochemistry, 76(3), 327-352

Rezai, A., Taylor, L., \& Foley, D. (2018). Economic growth, income distribution, and climate change. Ecological Economics, 146, 164-172.

Rushdi, A. M. A., \& Ba-Rukab, O. M. (2017). Map calculation of the Shapley-Shubik voting powers: an example of the European Economic Community. International Journal of Mathematical, Engineering and Management Sciences, 2(1), 17-29.

Schneising, O., Buchwitz, M., Burrows, J. P., Bovensmann, H., Bergamaschi, P., \& Peters, W. (2009). Three years of greenhouse gas column-averaged dry air mole fractions retrieved from satellite-Part 2 : Methane. Atmospheric Chemistry and Physics, 9(2), 443-465.

Shah, N. H., Patel, S. N., Satia, M. H., \& Thakkar, F. A. (2018). Optimal control for transmission of water pollutants. International Journal of Mathematical, Engineering and Management Sciences, 3(4), 381391.

Shvidenko, A., Schepaschenko, D., McCallum, I., \& Nilsson, S. (2010). Can the uncertainty of full carbon acconting of forest ecosystem be made acceptable to policymakers? Climate Change, 103(1-2), 137157.

Smith, J. B., \& Pitts G. J. (1997). Regional climate change scenarios for vulnerability and adaptation assessments. Climatic Change, 36(1-2), 3-21.

\section{Websites/Links}

VI National Communication on the Climate Change of Ukraine. (2014). Kiev: Ministry of Environment and Natural Resources of Ukraine, 323 p. http://www.seia.gov.ua/seia/document/638134.

Climate Change and Security in Eastern Europe. Regional Assessment Report. (2017). OSCE, Vienna: 100. https://www.osce.org/secretariat/355496. 